\title{
Heterogeneous Effects of Calorie Restriction on In Vivo Glucose Uptake and Insulin Signaling of Individual Rat Skeletal Muscles
}

\author{
Naveen Sharma ${ }^{1}$, Donel A. Sequea ${ }^{2}$, Carlos M. Castorena ${ }^{1}$, Edward B. Arias ${ }^{1}$, Nathan R. $\mathbf{Q i}^{3}$, \\ Gregory D. Cartee ${ }^{1,2,4 *}$
}

1 Muscle Biology Laboratory, School of Kinesiology, University of Michigan, Ann Arbor, Michigan, United States of America, 2 Department of Molecular and Integrative Physiology, University of Michigan, Ann Arbor, Michigan, United States of America, 3 Department of Internal Medicine, University of Michigan, Ann Arbor, Michigan, United States of America, $\mathbf{4}$ Institute of Gerontology, University of Michigan, Ann Arbor, Michigan, United States of America

\begin{abstract}
Calorie restriction (CR) (consuming $\sim 60 \%$ of ad libitum, $\mathrm{AL}$, intake) improves whole body insulin sensitivity and enhances insulin-stimulated glucose uptake by isolated skeletal muscles. However, little is known about CR-effects on in vivo glucose uptake and insulin signaling in muscle. Accordingly, 9-month-old male AL and CR (initiated when 3-months-old) Fischer $344 x$ Brown Norway rats were studied using a euglycemic-hyperinsulinemic clamp with plasma insulin elevated to a similar level $(\sim 140 \mu \mathrm{U} / \mathrm{ml})$ in each diet group. Glucose uptake (assessed by infusion of $\left[{ }^{14} \mathrm{C}\right]-2$-deoxyglucose, 2-DG), phosphorylation of key insulin signaling proteins (insulin receptor, Akt and Akt substrate of 160kDa, AS160), abundance of GLUT4 and hexokinase proteins, and muscle fiber type composition (myosin heavy chain, MHC, isoform percentages) were determined in four predominantly fast-twitch (epitrochlearis, gastrocnemius, tibialis anterior, plantaris) and two predominantly slow-twitch (soleus, adductor longus) muscles. CR did not result in greater GLUT4 or hexokinase abundance in any of the muscles, and there were no significant diet-related effects on percentages of MHC isoforms. Glucose infusion was greater for $C R$ versus $A L$ rats $(P<0.05)$ concomitant with significantly $(P<0.05)$ elevated 2-DG uptake in 3 of the 4 fasttwitch muscles (epitrochlearis, gastrocnemius, tibialis anterior), without a significant diet-effect on 2-DG uptake by the plantaris or either slow-twitch muscle. Each of the muscles with a CR-related increase in 2-DG uptake was also characterized by significant $(P<0.05)$ increases in phosphorylation of both Akt and AS160. Among the 3 muscles without a CR-related increase in glucose uptake, only the soleus had significant $(P<0.05)$ CR-related increases in Akt and AS160 phosphorylation. The current data revealed that CR leads to greater whole body glucose disposal in part attributable to elevated in vivo insulin-stimulated glucose uptake by fast-twitch muscles. The results also demonstrated that CR does not uniformly enhance either insulin signaling or insulin-stimulated glucose uptake in all muscles in vivo.
\end{abstract}

Citation: Sharma N, Sequea DA, Castorena CM, Arias EB, Qi NR, et al. (2013) Heterogeneous Effects of Calorie Restriction on In Vivo Glucose Uptake and Insulin Signaling of Individual Rat Skeletal Muscles. PLOS ONE 8(6): e65118. doi:10.1371/journal.pone.0065118

Editor: Ferenc Gallyas, University of Pecs Medical School, Hungary

Received February 13, 2013; Accepted April 22, 2013; Published June 3, 2013

Copyright: (c) 2013 Sharma et al. This is an open-access article distributed under the terms of the Creative Commons Attribution License, which permits unrestricted use, distribution, and reproduction in any medium, provided the original author and source are credited.

Funding: This work was supported by National Institutes of Health grants AG-010026, AG-013283, T32-AG000114, and DK-089503. The funders had no role in study design, data collection and analysis, decision to publish, or preparation of the manuscript.

Competing Interests: The authors have declared that no competing interests exist.

* E-mail: gcartee@umich.edu

\section{Introduction}

Calorie restriction $(\mathrm{CR})$ without malnutrition (consuming $\sim 60$ $75 \%$ of ad libitum, AL, intake) has been demonstrated to improve whole body insulin sensitivity in various species, including humans $[1,2,3]$, non-human primates [4], dogs [5], rats [6,7], and mice [8]. Because up to $80 \%$ of insulin-stimulated blood glucose clearance is taken up by skeletal muscle [9], it is reasonable to expect that CR leads to increased insulin-mediated glucose uptake in skeletal muscle. Supporting this idea, a number of studies using isolated mouse skeletal muscle $[10,11]$ or isolated $[12,13,14,15,16,17,18,19,20,21,22]$ or perfused rat [23] skeletal muscle have reported increased insulin-stimulated glucose uptake for $\mathrm{CR}$ versus $\mathrm{AL}$ animals.

The mechanisms that account for improved insulin-stimulated glucose uptake with CR have been frequently studied in skeletal muscle under ex vivo conditions. These studies have documented that when skeletal muscle is exposed to insulin ex vivo, CR can enhance the effect of insulin on selected proteins in the insulin signaling pathway that controls the subcellular distribution of GLUT4, the insulin-regulated glucose transporter protein. Phosphorylation of Akt (also known as protein kinase B) on Thr308 and Ser473 is essential for the full effect of insulin on glucose transport [10]. In this context, it is notable that the most consistent result of a series of studies on isolated muscles from $\mathrm{CR}$ versus AL rodents has been elevated insulin-induced phosphorylation of Akt on both sites $[10,12,13,22,24,25,26]$. Akt substrate of $160 \mathrm{kDa}$ (also known as AS160 or TBC1D4) is the most distal substrate of Akt that has been clearly linked to insulin's activation of GLUT4 translocation [27,28,29,30,31,32]. AS160 undergoes Akt-dependent phosphorylation on several sites, with Thr642 and Ser588 being the sites that appear to account for most of insulin's effect on GLUT4 translocation and glucose transport [28]. CR by 9 mo-old rats was recently reported to lead to greater insulin-mediated AS160 phosphorylation on both Thr642 and Ser588 in isolated epitro- 
chlearis muscle (composed predominantly of fast-twitch, type II, fibers), but not in isolated soleus muscle (composed predominantly of slow-twitch, type I, fibers) despite greater insulin-stimulated Akt phosphorylation in both muscles [22]. These results suggested that the mechanisms accounting for improved insulin-stimulated glucose uptake may not be entirely identical for skeletal muscles with differing fiber type profiles.

In contrast to the numerous studies of CR effects on glucose uptake by isolated skeletal muscles, apparently only one publication has evaluated the effects of several months of CR on insulinstimulated glucose uptake by individual skeletal muscles under in vivo conditions [7]. Despite having higher whole-body glucose uptake during a euglycemic-hyperinsulinemic clamp, the results of this study surprisingly indicated that CR by 8 mo-old rats (restricted to $\sim 80 \%$ of AL intake beginning at 5 mo-old) did not significantly increase insulin-stimulated glucose uptake by the skeletal muscles that were evaluated [7]. Apparently no previously published studies have reported the effects of $\mathrm{CR}$ on insulin signaling by skeletal muscle in response to physiologic insulin concentrations.
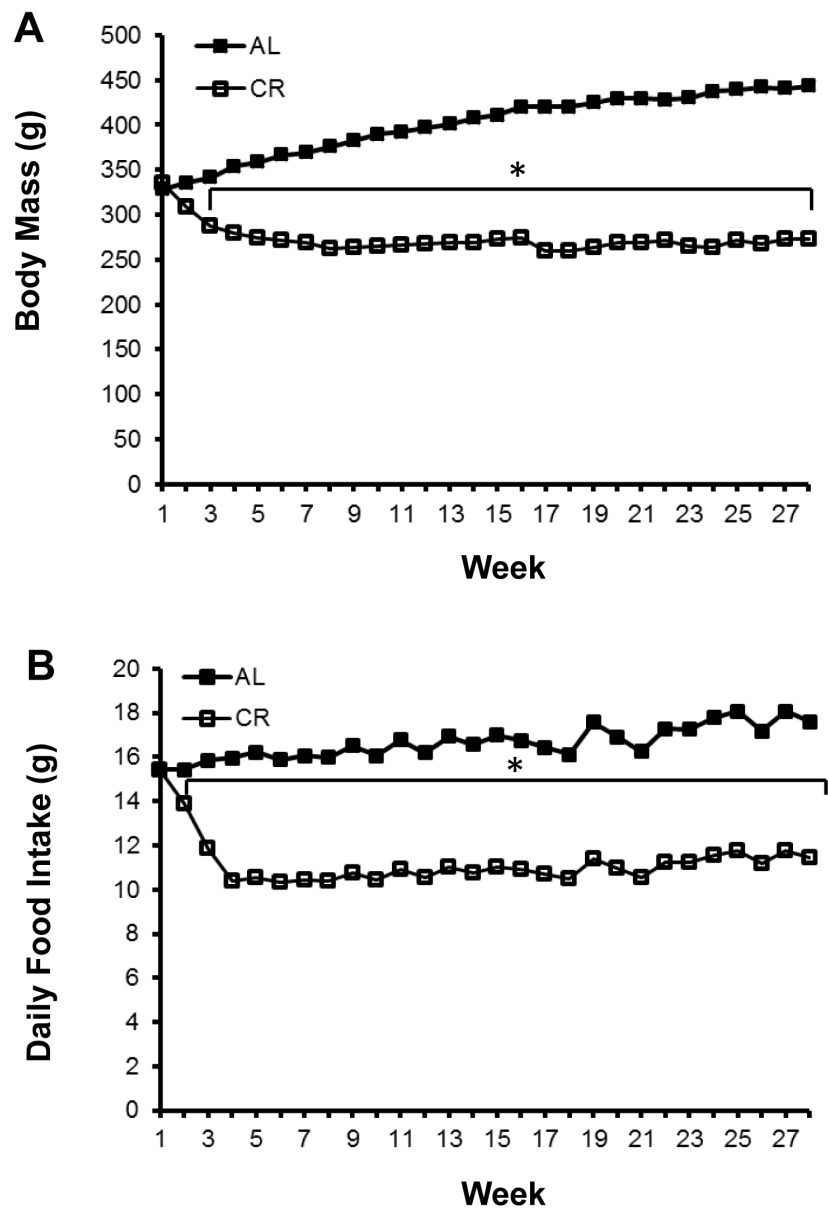

Figure 1. Rat body mass (A) and daily food intake (B). Filled boxes are the AL group and open bars are the CR group. Rats were weighed weekly. Weekly food allotment for the CR group was based on AL group's food intake for the previous week. When rats were $\sim 3$ moold, the food intake of the CR group was reduced to $90 \%$ of AL for a week, $75 \%$ of $A L$ for the following week, and continued at $60-65 \%$ of $A L$ thereafter. ${ }^{*} \mathrm{P}<0.05 \mathrm{AL}$ versus $\mathrm{CR}$ group. Data are means. For clarity, $\mathrm{SE}$ bars are not included.

doi:10.1371/journal.pone.0065118.g001
The current research was performed to extend the very limited knowledge available about CR effects on insulin signaling and glucose uptake by skeletal muscle under in vivo conditions. The primary goal of this study was to compare adult (9 mo-old) CR (60-65\% of AL intake initiated at 3 mo-old) versus age-matched AL rats with regard to glucose uptake and key insulin signaling steps in vivo in multiple muscles stimulated by a physiologic insulin concentration during a euglycemic-hyperinsulinemic clamp. We studied four muscles predominantly composed of fast-twitch (type II) fibers (epitrochlearis, gastrocnemius, tibialis anterior, and plantaris), and two muscles predominantly composed of slow-twitch (type I) fibers (adductor longus and soleus). Because it seemed possible that CR might induce a shift in fiber type composition, we assessed the effect of CR on fiber-type composition in each of these muscles. We hypothesized that CR would influence insulin signaling and glucose uptake in multiple muscles, but the specific CR effects on insulin signaling would not be identical for muscles with different fiber-type compositions.

\section{Methods}

\section{Materials}

Unless otherwise noted, all chemicals were purchased from Fisher Scientific (Hanover Park, IL) or Sigma-Aldrich (St. Louis, MO). Reagents and apparatus for SDS-PAGE and immunoblotting were obtained from Bio-Rad Laboratories (Hercules, CA).

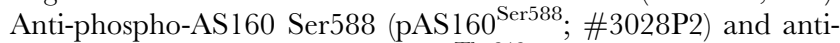

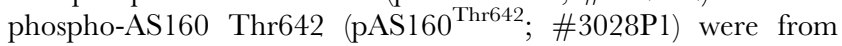
Symansis (Timaru, New Zealand). Anti-phospho-Akt Thr308

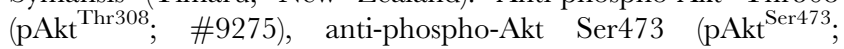
\#9272), anti-hexokinase II (\#2867), and anti-rabbit IgG-horseradish peroxidase conjugate (\#7074) were from Cell Signaling Technology (Danvers, MA). Anti-phospho-IR Tyr1162/1163

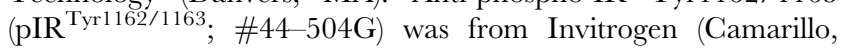
CA). Anti-sheep IgG horseradish peroxidase conjugate (\#12-342) was from Millipore (Billerica, MA). Anti-GLUT4 was provided by Dr. Samuel Cushman (NIH, Bethesda, MD). West Dura Extended Duration Substrate (\#34075) and the bicinchoninic acid protein assay kit (\#23227) were from Thermo Scientific (Rockford, IL).

\section{Animal Care}

Procedures for animal care were approved by the University of Michigan Committee on Use and Care of Animals. Male Fischer $344 \times$ Brown Norway, F1 generation rats were obtained at 3 months of age from Harlan (Indianapolis, IN). Animals were housed individually in shoebox cages and maintained on a 12:12-h light-dark cycle (lights out at 17:00) in specific pathogen-free conditions. The feeding protocol for both the ad libitum (AL) group and the calorie restricted (CR) group has been previously described [22], but briefly the CR group was restricted to $60-65 \%$ of AL intake gradually over 3 weeks $(90 \%, 75 \%, 60-65 \%)$. Subsequently, the CR group continued to receive $60-65 \%$ of the intake of the AL group daily for $\sim 6$ months.

\section{Euglycemic-Hyperinsulinemic Clamp}

After $\sim 6$ months at the University of Michigan facility, AL and GR rats had catheters surgically placed into the jugular vein and carotid artery one week prior to a euglycemic-hyperinsulinemic clamp experiment as previously described [33]. At approximately 0800 on the day of the clamp experiment, food was removed from rat cages $(\sim 5 \mathrm{~h}$ prior to the start of the clamp procedure). The clamp protocol consisted of a 120 min experimental period $(\mathrm{t}=0$ to $120 \mathrm{~min})$. At $\mathrm{t}=-10 \mathrm{~min}$, an arterial blood sample $(\sim 100 \mu \mathrm{l})$ was taken for assessment of basal levels of insulin and glucose. The 
Table 1. Relative myosin heavy chain (MHC) isoform composition of rat skeletal muscle.

\begin{tabular}{|c|c|c|c|c|c|c|c|c|}
\hline & \multicolumn{2}{|c|}{$\%$ MHC I } & \multicolumn{2}{|c|}{ \% MHC IIA } & \multicolumn{2}{|c|}{ \% MHC IIX } & \multicolumn{2}{|c|}{$\%$ MHC IIB } \\
\hline & AL & CR & AL & CR & AL & CR & AL & CR \\
\hline Epitrochlearis & $5 \pm 2$ & $3 \pm 1$ & $8 \pm 1$ & $6 \pm 1$ & $27 \pm 3$ & $24 \pm 1$ & $60 \pm 4$ & $67 \pm 2$ \\
\hline Gastrocnemius & $13 \pm 3$ & $11 \pm 2$ & $13 \pm 2$ & $12 \pm 1$ & $35 \pm 3$ & $33 \pm 2$ & $39 \pm 5$ & $44 \pm 3$ \\
\hline Tibialis Anterior & $3 \pm 1$ & $3 \pm 1$ & $11 \pm 2$ & $11 \pm 2$ & $28 \pm 1$ & $30 \pm 1$ & $58 \pm 3$ & $56 \pm 3$ \\
\hline Plantaris & $9 \pm 3$ & $10 \pm 1$ & $18 \pm 2$ & $17 \pm 1$ & $41 \pm 2$ & $36 \pm 2$ & $32 \pm 5$ & $37 \pm 3$ \\
\hline Soleus & $99 \pm 1$ & $98 \pm 1$ & $0 \pm 0$ & $1 \pm 1$ & $1 \pm 1$ & $1 \pm 1$ & $0 \pm 0$ & $0 \pm 0$ \\
\hline Adductor Longus & $74 \pm 6$ & $88 \pm 5$ & $8 \pm 3$ & $3 \pm 1$ & $18 \pm 4$ & $9 \pm 3$ & $0 \pm 0$ & $0 \pm 0$ \\
\hline
\end{tabular}

Values are means \pm SE. MHC isoforms were separated by SDS-PAGE, which were stained with Coomassie Blue. Resulting bands were quantified by densitometry and were expressed as relative values (\%) for each of the 6 skeletal muscles.

doi:10.1371/journal.pone.0065118.t001

insulin infusion was begun at $\mathrm{t}=0$ with a primed-continuous infusion of insulin (Novo Nordisk, Princeton, NJ). A stable plasma glucose concentration $(120-130 \mathrm{mg} / \mathrm{dL})$ was maintained during the clamp by measuring blood glucose every 10 min starting at $\mathrm{t}=0$ and infusing $50 \%$ glucose solution at variable rates accordingly. Plasma insulin concentrations were determined from samples taken at $\mathrm{t}=-10$ and $120 \mathrm{~min}$. Insulin infusion rates were selected with the goal of achieving similar plasma values for insulin in the $\mathrm{CR}$ group compared to the $\mathrm{AL}$ group. $\mathrm{CR}$ rats have a higher rate of insulin clearance as indicated by the elevated Cpeptide:insulin ratio in GR compared to AL rats [22] and by the greater insulin binding in the liver of $\mathrm{CR}$ versus $\mathrm{AL}$ rats after radiolabelled insulin injection [34]. Therefore, to achieve similar plasma insulin concentrations in CR and AL rats, insulin was infused at a higher rate for $\mathrm{CR}$ rats $\left(4.7\right.$ to $\left.6.0 \mathrm{mU} \cdot \mathrm{kg}^{-1} \cdot \mathrm{min}^{-1}\right)$ versus AL rats $\left(4.0 \mathrm{mU} \cdot \mathrm{kg}^{-1} \cdot \mathrm{min}^{-1}\right)$. To estimate glucose uptake

\section{2-DG Uptake}

\section{Predominantly Fast-Twitch}

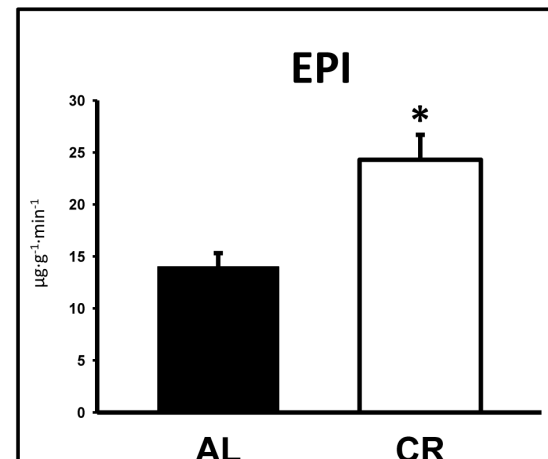

AL

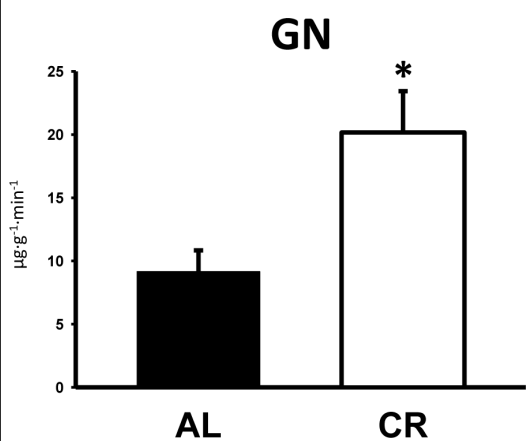

TA

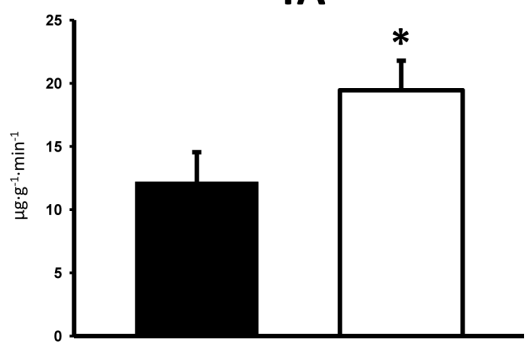

AL

CR

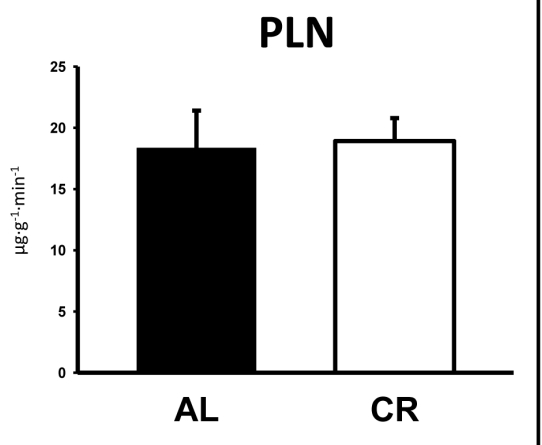

Predominantly Slow-Twitch

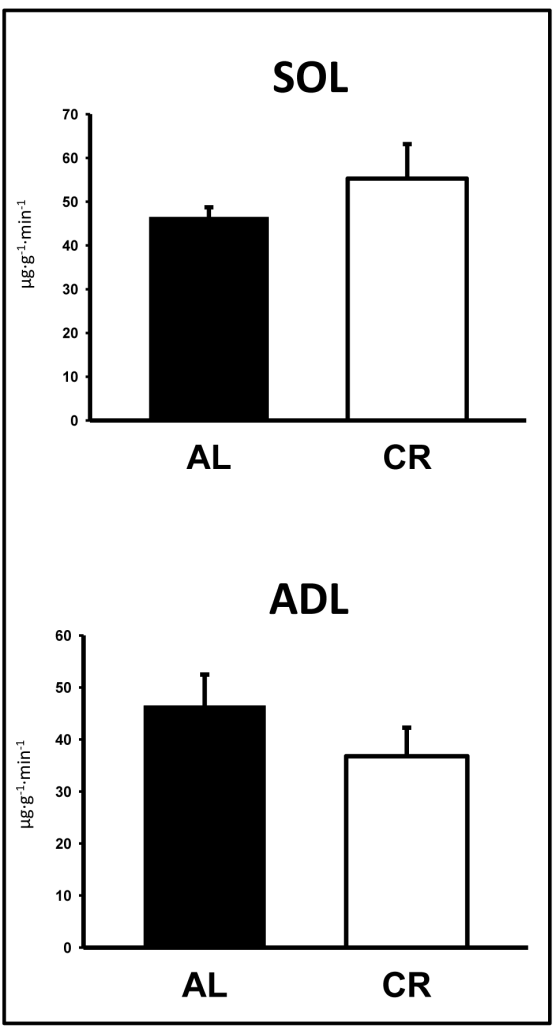

Figure 2. 2-Deoxyglucose (2-DG) uptake in predominantly fast-twitch and predominantly slow-twitch muscles. EPI, epitrochlearis; GN, gastrocnemius; TA, tibialis anterior; PLN, plantaris; SOL, soleus; ADL, adductor longus. Filled bars are the AL group and open bars are the CR group. ${ }^{*} \mathrm{P}<0.05, \mathrm{CR}$ versus AL. Data are means $\pm \mathrm{SE} . \mathrm{n}=6-13$ rats per treatment group.

doi:10.1371/journal.pone.0065118.g002 


\section{plR Tyr1162/1163}

Predominantly Fast-Twitch

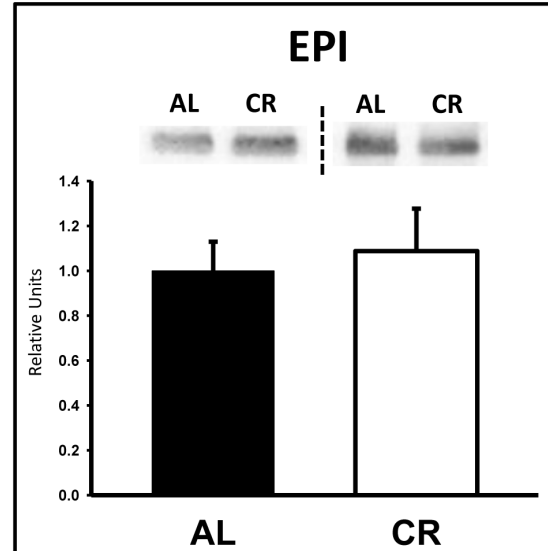

GN

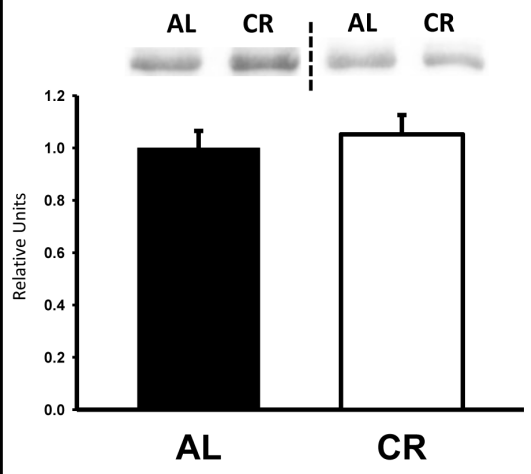

TA

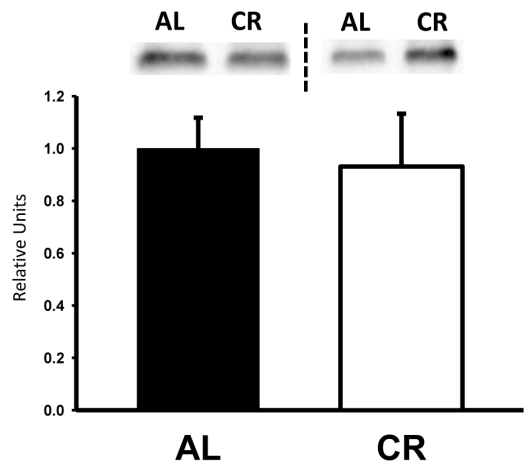

PLN

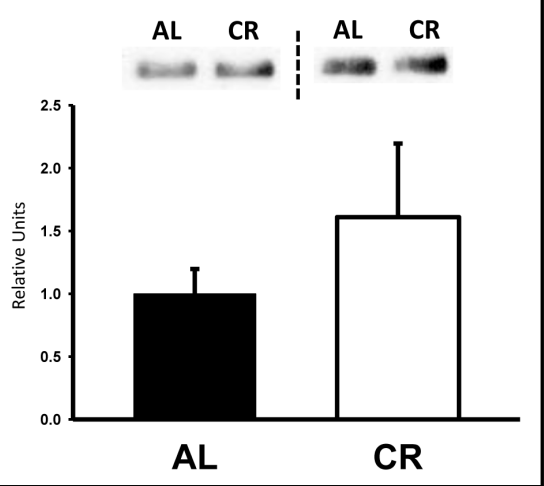

Predominantly Slow-Twitch

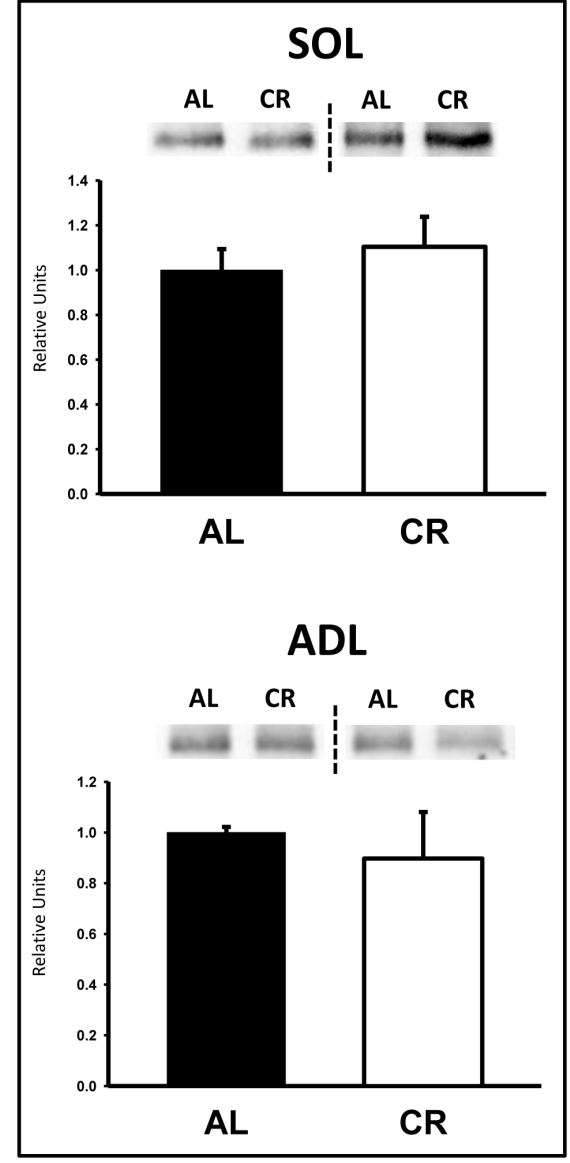

Figure 3. Insulin receptor Tyr1162/1163 phosphorylation $\left(\mathrm{pIR}^{\mathrm{Ty} 1162 / 1163}\right)$ in predominantly fast-twitch and predominantly slowtwitch muscles. EPI, epitrochlearis; GN, gastrocnemius; TA, tibialis anterior; PLN, plantaris; SOL, soleus; ADL, adductor longus. Filled bars are the AL group and open bars are the CR group. Values are normalized to the average value of the AL samples on each blot. Each graph in Figures 3 to 9 is accompanied by representative blots from two muscles from AL and CR rats (the dashed line denotes two independent blots). Data are means \pm SE. $\mathrm{n}=6-8$ rats per treatment group.

doi:10.1371/journal.pone.0065118.g003

in skeletal muscle, a bolus injection of $\left[1-{ }^{14} \mathrm{C}\right]$-2-deoxyglucose $\left(\left[{ }^{14} \mathrm{C}\right] 2 \mathrm{DG}\right.$; PerkinElmer, Waltham, MA $)$ was given at $\mathrm{t}=120 \mathrm{~min}$ while continuously maintaining the euglycemic-hyperinsulinemic steady-state. Blood samples were taken at 2, 5, 10, 15, and 25 min after the injection for determination of plasma $\left[{ }^{14} \mathrm{C}\right] 2 \mathrm{DG}$ radioactivity. At the end of the experiment, rats were anesthetized with an intravenous infusion of sodium pentobarbital and muscles were rapidly excised and freeze-clamped with aluminum tongs cooled in liquid nitrogen and stored at $-80^{\circ} \mathrm{C}$ until later processing.

\section{Plasma Analysis}

Plasma glucose during clamps was measured using an AccuChek glucometer (Roche, Germany). Plasma insulin was measured using rat/mouse insulin ELISA kits (R\&D Systems, Minneapolis, $\mathrm{MN})$.

\section{Skeletal Muscle Glucose Uptake}

For glucose uptake analysis, muscle was homogenized in $0.5 \%$ perchloric acid and centrifuged at $2000 \mathrm{~g}$ for $15 \mathrm{~min}$ at $4^{\circ} \mathrm{C}$. The supernatants were neutralized with potassium hydroxide $(5 N)$. An aliquot of the homogenate was quantified by liquid scintillation counting to determine total tissue values (disintegrations per minute, dpm) for the sum of $\left[{ }^{14} \mathrm{C}\right] 2$-deoxyglucose $\left(\left[{ }^{14} \mathrm{C}\right] 2 \mathrm{DG}\right)$ and $\left[{ }^{14} \mathrm{C}\right]$ 2-deoxyglucose phosphate $\left(\left[{ }^{14} \mathrm{C}\right] 2 \mathrm{DGP}\right)$. Another aliquot was deproteinized with zinc sulfate $(0.3 \mathrm{~N})$ and barium hydroxide $(0.3 \mathrm{~N})$ to precipitate $\left[{ }^{14} \mathrm{C}\right]$ 2-deoxyglucose-6-phosphate $\left(\left[{ }^{14} \mathrm{C}\right] 2 \mathrm{DG} 6 \mathrm{P}\right)$ and quantify $\left[{ }^{14} \mathrm{C}\right] 2 \mathrm{DG}$ in the supernatant. The value for the $\left[{ }^{14} \mathrm{C}\right] 2 \mathrm{DG}$ in the supernatant $(\mathrm{dpm})$ was subtracted from the total tissue $\left[{ }^{14} \mathrm{C}\right] 2 \mathrm{DG}$ and $\left[{ }^{14} \mathrm{C}\right] 2 \mathrm{DGP}(\mathrm{dpm})$ to calculate the glucose uptake rate as indicated by the skeletal muscle $\left[{ }^{14} \mathrm{C}\right] 2$ DGP accumulation [35].

\section{Relative Abundance of Myosin Heavy Chain (MHC) Isoforms}

For MHC analysis, muscle was homogenized in pre-chilled glass tissue-grinding tubes (Kontes, Vineland, NJ) containing cold Tissue Protein Extraction Reagent (TPER; Thermo Scientific, Rockford, IL; \#78510) supplemented with $1 \mathrm{mM}$ EDTA, $1 \mathrm{mM}$ EGTA, $2.5 \mathrm{mM}$ sodium pyrophosphate, $1 \mathrm{mM}$ sodium vanadate 


\section{pAkt Ser473}

\section{Predominantly Fast-Twitch}

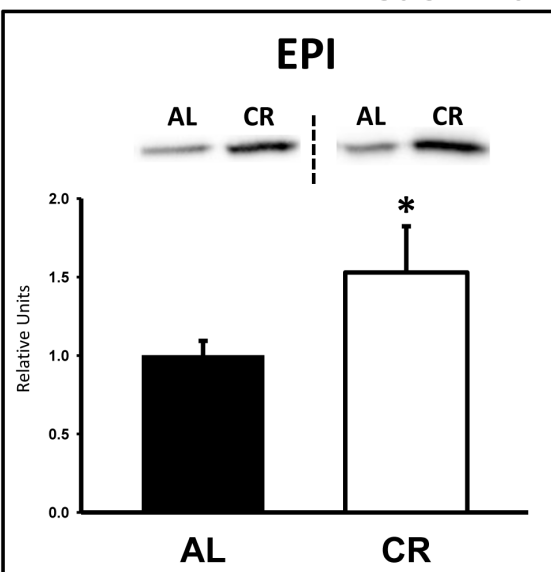

GN

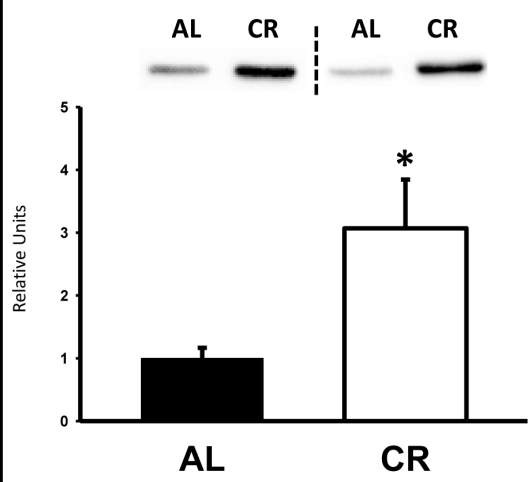

TA

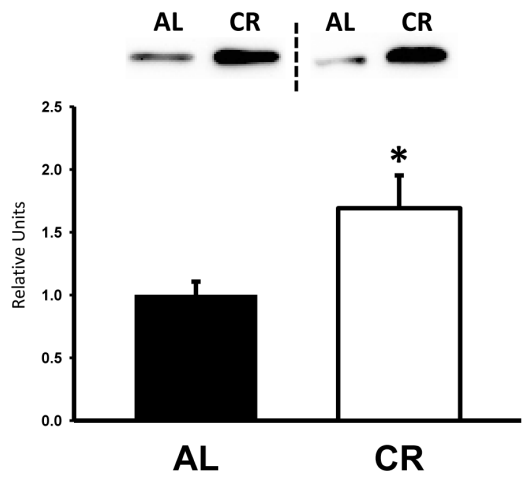

PLN

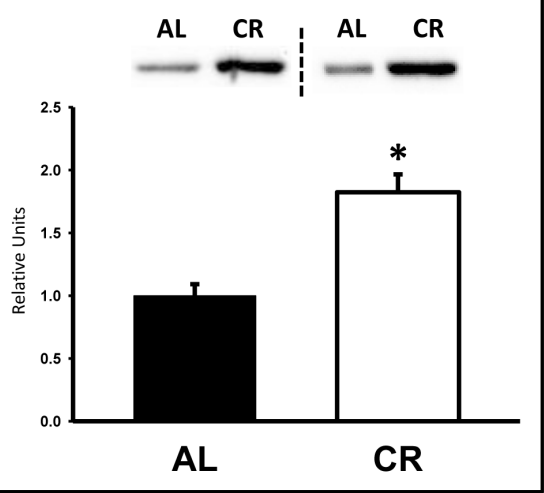

Predominantly Slow-Twitch

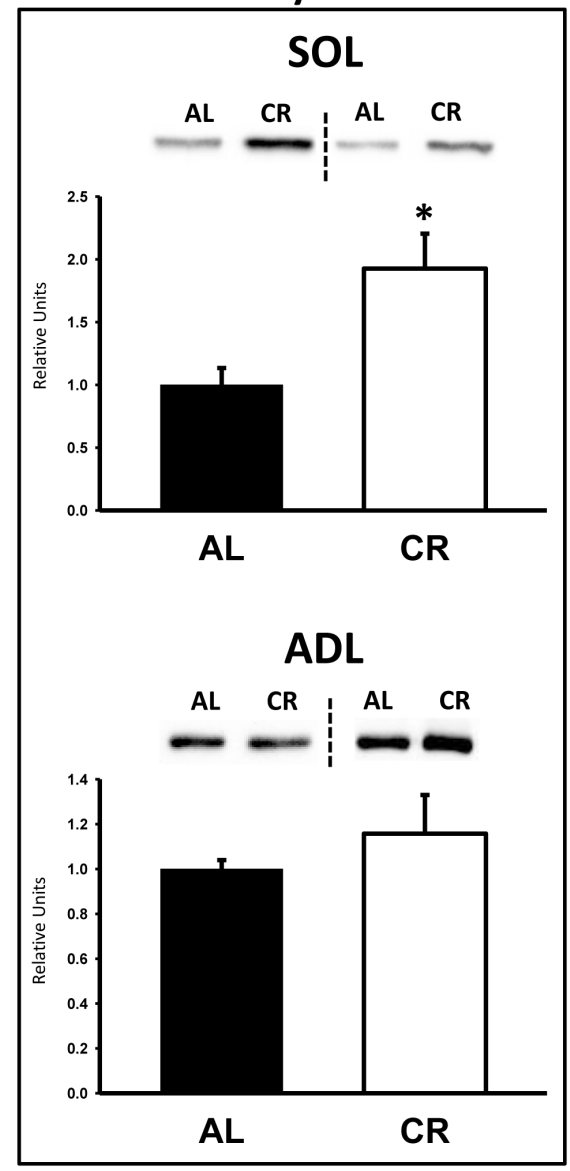

Figure 4. Akt Ser473 phosphorylation $\left(\mathrm{pAkt}^{\mathrm{Ser473}}\right)_{\text {in }}$ predominantly fast-twitch and predominantly slow-twitch muscles. EPI, epitrochlearis; GN, gastrocnemius; TA, tibialis anterior; PLN, plantaris; SOL, soleus; ADL, adductor longus. Filled bars are the AL group and open bars are the $C R$ group. Values are normalized to the average value of the $A L$ samples on each blot. ${ }^{*} P<0.05, C R$ versus $A L$. Data are means $\pm S E$. $n=6-$ 8 rats per treatment group.

doi:10.1371/journal.pone.0065118.g004

$\left(\mathrm{Na}_{3} \mathrm{VO}_{4}\right), 1 \mathrm{mM}$ B-glycerophosphate, $1 \mu \mathrm{g} / \mathrm{ml}$ leupeptin, and $1 \mathrm{mM}$ phenylmethylsulfonyl fluoride (PMSF). Protein concentrations were determined using the bicinchoninic acid method (Pierce Biotechnology, Rockford, IL; \#23225). Laemmli sample buffer $(2 \times)$ was then added to $5 \mu \mathrm{g}$ of the whole homogenate prior to heating for $10 \mathrm{~min}$ at $90^{\circ} \mathrm{C}$. Samples where then loaded on to gels modified from [36] for SDS-PAGE [Final reagent concentrations for separating gel: $6.5 \%$ acrylamide-bis (50:1), 30\% glycerol, $210 \mathrm{mM}$ Tris-HCl (pH 7.4), $105 \mathrm{mM}$ glycine, $0.4 \%$ SDS, $19 \%$ $\mathrm{H}_{2} 0,0.1 \%$ ammonium persulfate, $0.05 \%$ TEMED]. Samples were run at a constant voltage $(50 \mathrm{~V})$ for $1 \mathrm{~h}$ at $4^{\circ} \mathrm{C}$ with continuous mixing by a magnetic stir bar inside the electrophoresis apparatus. After the initial hour, the power supply was switched from constant voltage mode to the constant current mode. The current value observed at the end of the initial hour was subsequently maintained for an additional $21-22 \mathrm{~h}$ at $4^{\circ} \mathrm{C}$. Gels were then stained with Coomassie Brilliant Blue (\#161-0436, Biorad) overnight at room temperature while gently rotating. The gels were then destained for $4-6 \mathrm{~h}$ in $20 \%$ methanol and $10 \%$ acetic acid solution (destained solution was replaced with fresh solution every 30-45 min). MHC bands were quantified using densitometry (AlphaEase FC, Alpha Innotech, San Leandro, CA).

\section{Immunoblotting}

For immunoblotting analysis, muscle was transferred to microfuge tubes and homogenized in ice-cold TPER buffer as stated above ( $1 \mathrm{ml} / \mathrm{muscle})$ using Qiagen a TissueLyser II (Valencia, CA). Homogenates were then transferred to microfuge tubes, rotated for $1 \mathrm{~h}$ at $4^{\circ} \mathrm{C}$, and then centrifuged $(15,000 \mathrm{~g})$ for $15 \mathrm{~min}\left(4^{\circ} \mathrm{C}\right)$ to remove insoluble material. The immunoblotting procedure has been previously described [33]. Immunoreactive proteins were quantified by densitometry and normalized to the average value of the AL samples on each blot.

\section{Glucose-6-phosphate (G6P) and Fructose-6-phosphate (F6P) Concentrations}

Frozen muscle was homogenized with a glass mortar and pestle in $0.4 \mathrm{ml}$ of cold $3 \mathrm{M}$ perchloric acid and $1 \mathrm{ml}$ of $\mathrm{H}_{2} 0$, transferred to a microfuge tube then centrifuged $(5000 \mathrm{~g})$ for $10 \mathrm{~min}\left(4^{\circ} \mathrm{C}\right)$. The supernatant $(1.2 \mathrm{ml})$ was then neutralized to a $\mathrm{pH}$ of 7.0 and brought to a volume of $3.0 \mathrm{ml}$ with $\mathrm{H}_{2} \mathrm{O}$ in a polypropylene tube, then centrifuged $(5000 \mathrm{~g})$ for $15 \mathrm{~min}\left(4^{\circ} \mathrm{C}\right)$. The resulting supernatant was used in the determination of G6P and F6P concentrations by a fluorometric procedure as previously de- 


\section{pAkt Thr308}

\section{Predominantly Fast-Twitch}

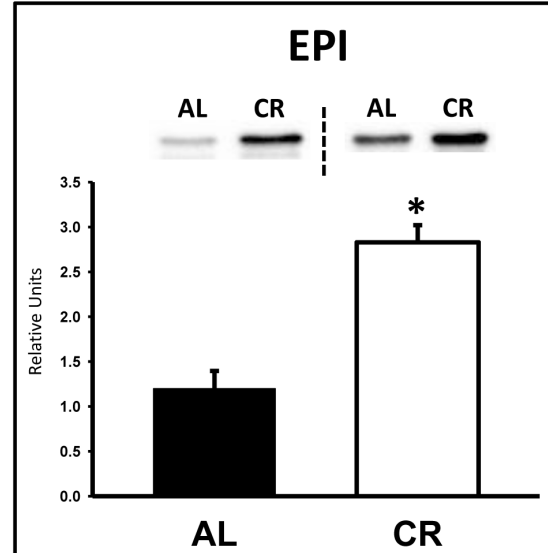

GN

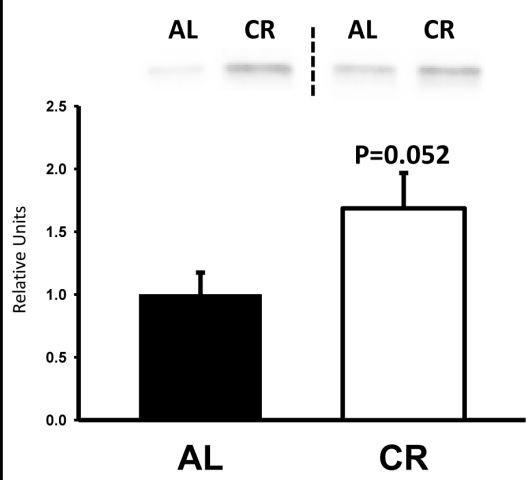

TA

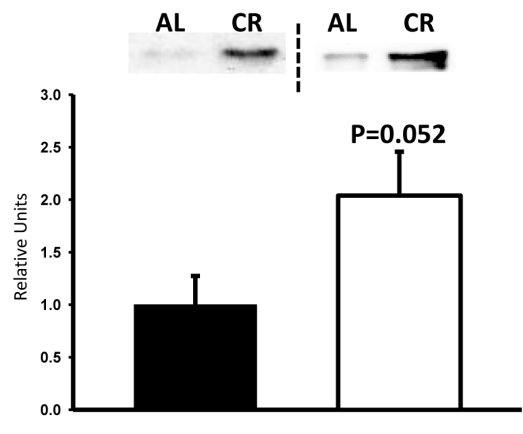

AL

\section{PLN}

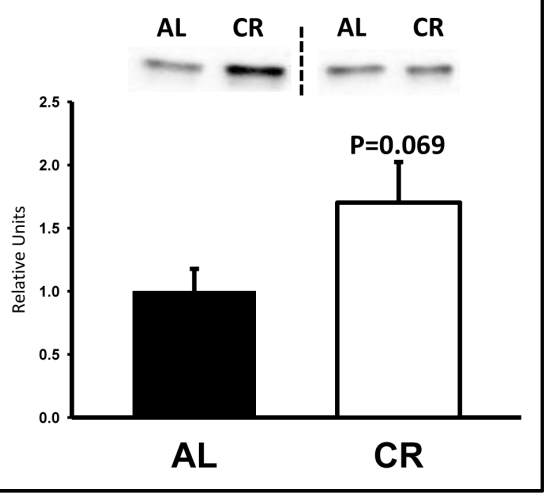

Predominantly Slow-Twitch SOL

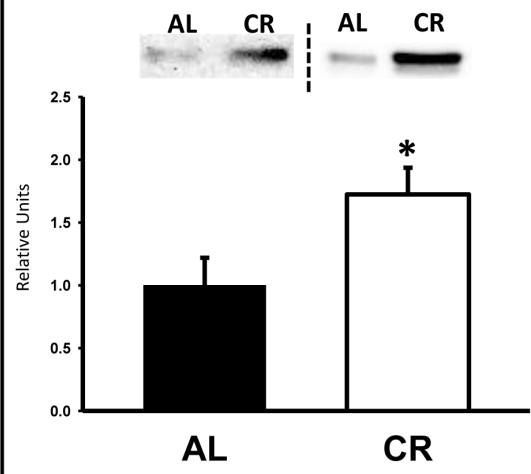

ADL

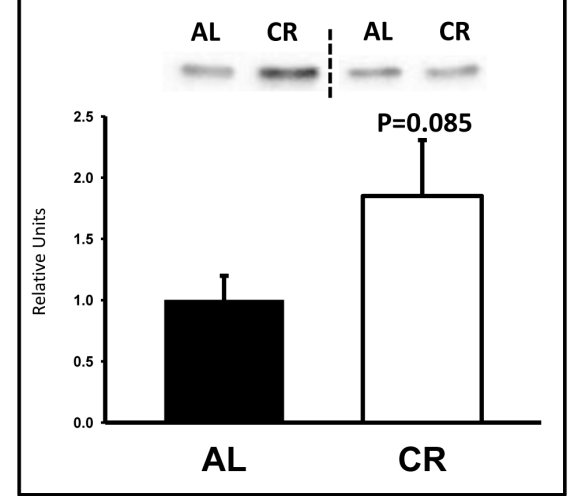

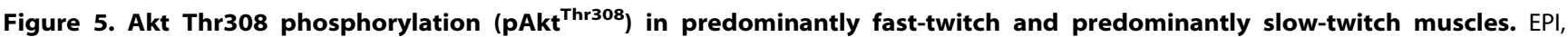
epitrochlearis; GN, gastrocnemius; TA, tibialis anterior; PLN, plantaris; SOL, soleus; ADL, adductor longus. Filled bars are the AL group and open bars are the CR group. Values are normalized to the average value of the AL samples on each blot. ${ }^{*} P<0.05, C R$ versus $A L$. Data are means $\pm S E$. $n=5-$ 8 rats per treatment group.

doi:10.1371/journal.pone.0065118.g005

scribed [37]. Briefly, a Model TD-700 Fluorometer (Turner Designs, Sunnyvale, CA) was used to determine the fluorescence values in samples, and the sample concentrations of G6P and F6P were determined based on the standard curves that were prepared by serial dilutions of analytical grade G6P and F6P (the G6P and F6P values for all of the muscle samples tested were within the range of the standard curves).

\section{Statistical Analyses}

Data were analyzed using SigmaPlot, version 11.0 (Systat Software, San Jose, CA). We performed a student's t-test for each of the direct comparisons between the two diet groups (AL versus GR). Data are presented as means \pm SE. A P value $<0.05$ was accepted as statistically significant.

\section{Results}

\section{Body Mass and Daily Food Intake}

Weekly body mass is shown in Figure 1A. Final body mass of the AL group was significantly $(\mathrm{P}<0.0001)$ greater than the $\mathrm{CR}$ group (443.36 $\pm 12.47 \mathrm{~g}$ vs. $272.60 \pm 7.34 \mathrm{~g}$ ). As expected, the feeding protocol resulted in the daily food intake of the CR group being progressively reduced during the initial 3 weeks of the intervention, and the CR intake was maintained at $60-65 \%$ of the AL group from week 3 onward (Fig. 1B).

Plasma Glucose, Plasma Insulin, and Glucose Infusion Rate

The baseline plasma glucose concentration was not significantly different between AL $(106.5 \pm 2.7 \mathrm{mg} / \mathrm{dl})$ and $\mathrm{CR}$ $(100.9 \pm 4.24 \mathrm{mg} / \mathrm{dl})$. Baseline insulin levels were greater $(\mathrm{P}<0.005)$ for $\mathrm{AL}(53.7 \pm 5.6 \mu \mathrm{U} / \mathrm{ml})$ versus $\mathrm{CR}(28.3 \pm 4.5 \mu \mathrm{U} /$ $\mathrm{ml})$ rats. Glucose levels during the clamp were maintained at $120.7 \pm 2.7 \mathrm{mg} / \mathrm{dl}$ for AL and 126.1 $\pm 2.4 \mathrm{mg} / \mathrm{dl} \mathrm{CR}$. Insulin levels during the clamp were similar for $\mathrm{AL}(141.3 \pm 9.1 \mu \mathrm{U} / \mathrm{ml})$ and $\mathrm{CR}$ $(140.3 \pm 6.7 \mu \mathrm{U} / \mathrm{ml})$. Glucose infusion rates were $78 \%$ higher $(\mathrm{P}<0.001)$ in $\mathrm{CR} \quad\left(31.7 \pm 1.6 \mathrm{mg} / \mathrm{kg}^{-1} \times \mathrm{min}^{-1}\right)$ versus $\mathrm{AL}$ $\left(17.8 \pm 0.8 \mathrm{mg} / \mathrm{kg}^{-1} \times \mathrm{min}^{-1}\right)$ rats. 


\section{pAS160 Thr642}

Predominantly Fast-Twitch

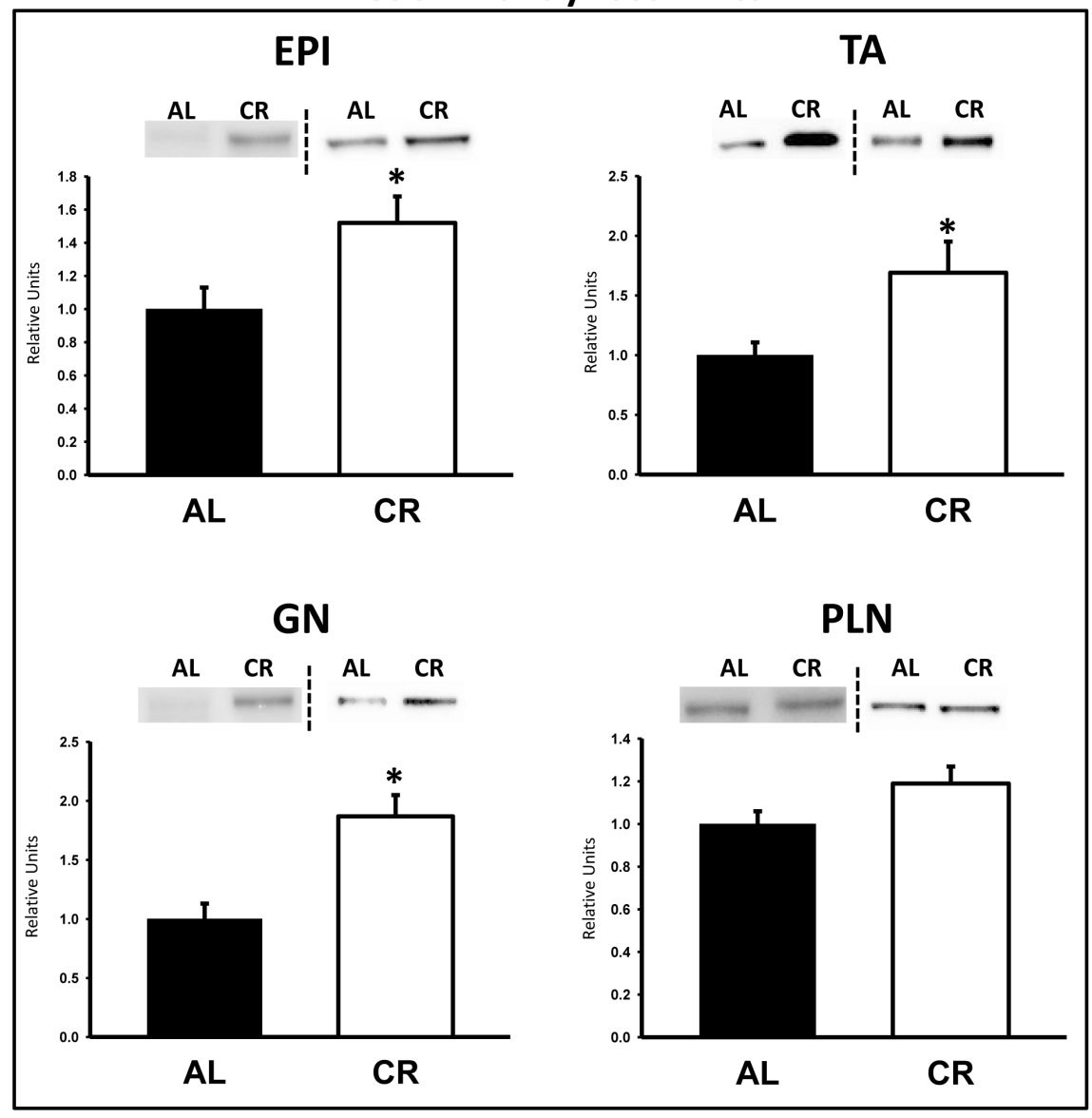

Predominantly Slow-Twitch

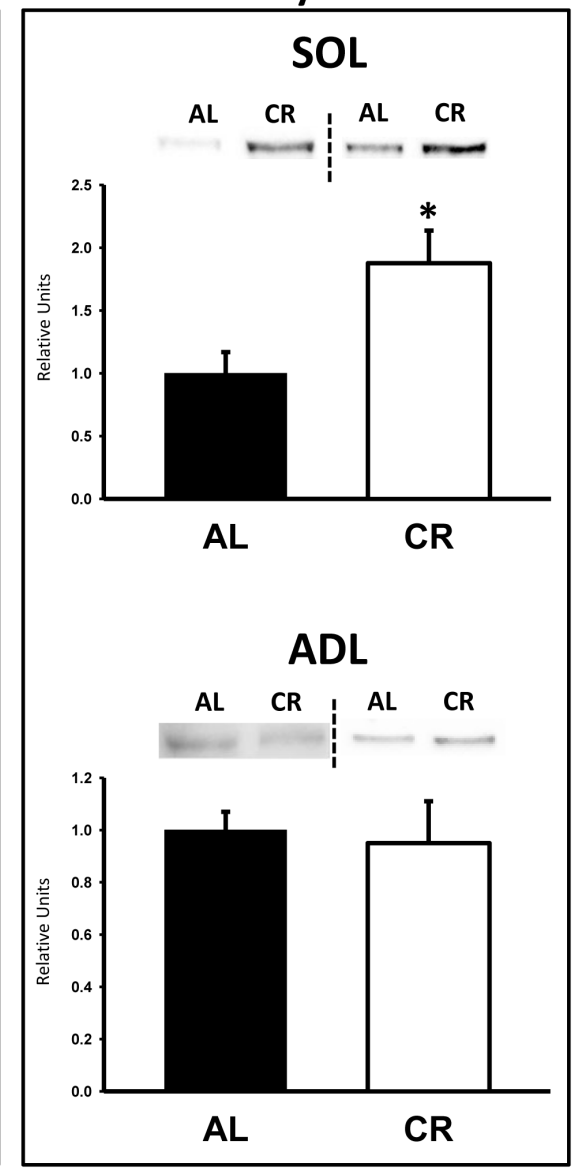

Figure 6. AS160 Thr642 phosphorylation (pAS160 ${ }^{\text {Thr642 }}$ ) in predominantly fast-twitch and predominantly slow-twitch muscles. EPI, epitrochlearis; GN, gastrocnemius; TA, tibialis anterior; PLN, plantaris; SOL, soleus; ADL, adductor longus. Filled bars are the AL group and open bars are the CR group. Values are normalized to the average value of the $A L$ samples on each blot. ${ }^{*} P<0.05, C R$ versus $A L$. Data are means $\pm S E$. $n=6-$ 8 rats per treatment group.

doi:10.1371/journal.pone.0065118.g006

\section{Relative Abundance of Myosin Heavy Chain (MHC) Isoforms}

There were no significant diet effects on the percentages of the MHC isoforms (I, IIA, IIX, IIB) in any of the muscles that were studied (Table 1).

\section{2-Deoxy-D-glucose Uptake}

2-DG uptake was significantly $(\mathrm{P}<0.05)$ greater in the epitrochlearis, tibialis anterior, and gastrocnemius for $\mathrm{CR}$ versus $\mathrm{AL}$ rats (Fig. 2). There were was no significant diet effects for 2DG uptake in the plantaris, soleus, or adductor longus (Fig. 2).

\section{Immunoblotting}

There were no significant differences between AL and CR rats on insulin receptor (IR) Tyr1162/1163 phosphorylation (pIRTyr1162/1163) in any of the muscles (Fig. 3). Akt Ser473 phosphorylation $\left(\mathrm{pAkt}^{\mathrm{Ser} 473}\right)$ was significantly $(\mathrm{P}<0.05)$ greater in the epitrochlearis, gastrocnemius, tibialis anterior, plantaris, and soleus for $\mathrm{CR}$ versus $\mathrm{AL}$ rats, but there was no significant diet effect in the adductor longus (Fig. 4). Akt Thr308 phosphorylation $\left(\mathrm{pAkt}^{\mathrm{Thr} 308}\right)$ was significantly $(\mathrm{P}<0.05)$ greater in the epitrochlearis and soleus, and had non-significant trends in the gastrocnemius $(\mathrm{P}=0.052)$, tibialis anterior $(\mathrm{P}=0.052)$, plantaris $(\mathrm{P}=0.069)$, and adductor longus $(\mathrm{P}=0.085)$ for $\mathrm{CR}$ versus $\mathrm{AL}$ rats $(\mathrm{Fig} .5)$. AS160 Thr642 phosphorylation (pAS160 ${ }^{\text {Thr642 }}$ ) was significantly $(\mathrm{P}<0.05)$ greater in the epitrochlearis, tibialis anterior, gastrocnemius, and soleus for $\mathrm{CR}$ versus $\mathrm{AL}$ rats, but there was not a significant diet effect in the plantaris or the adductor longus (Fig. 6). AS160 Ser588 phosphorylation (pAS160 ${ }^{\text {Ser588 }}$ ) was significantly $(\mathrm{P}<0.05)$ greater in the epitrochlearis and the tibialis anterior, and there was a non-significant trend in the plantaris $(\mathrm{P}=0.06)$ for greater values in $\mathrm{CR}$ versus AL rats, but there was not a significant diet effect in the gastrocnemius, soleus, or the adductor longus (Fig. 7). GLUT4 protein in the gastrocnemius was slightly, but significantly $(\mathrm{P}<0.05)$ lower for $\mathrm{CR}$ versus $\mathrm{AL}$ rats $(\mathrm{Fig}$. 8). There was no significant difference between $\mathrm{AL}$ and $\mathrm{CR}$ groups for hexokinase abundance in any of the muscles studied (Fig. 9). 
pAS160 16 Ser588

\section{Predominantly Fast-Twitch}

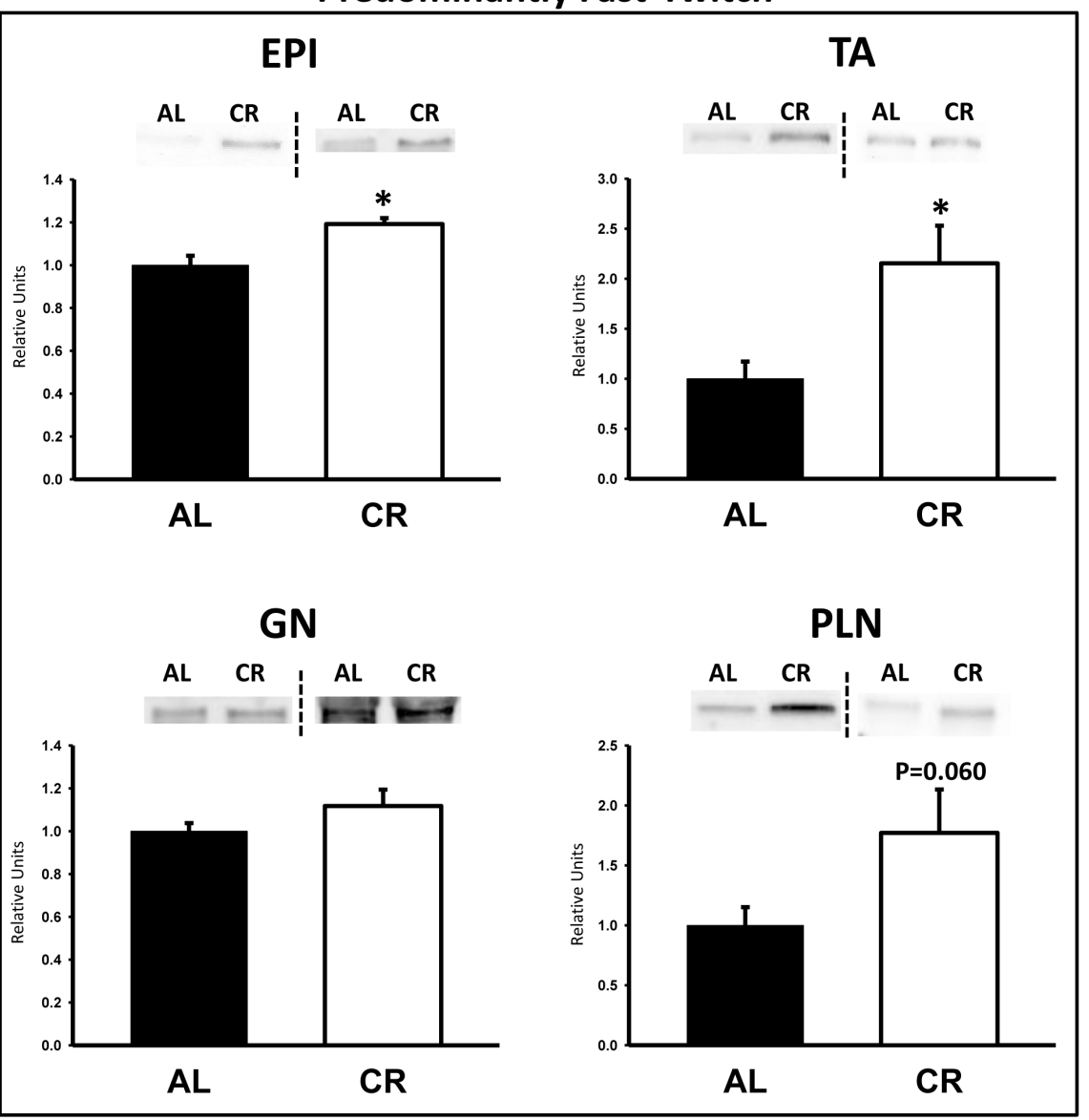

Predominantly Slow-Twitch

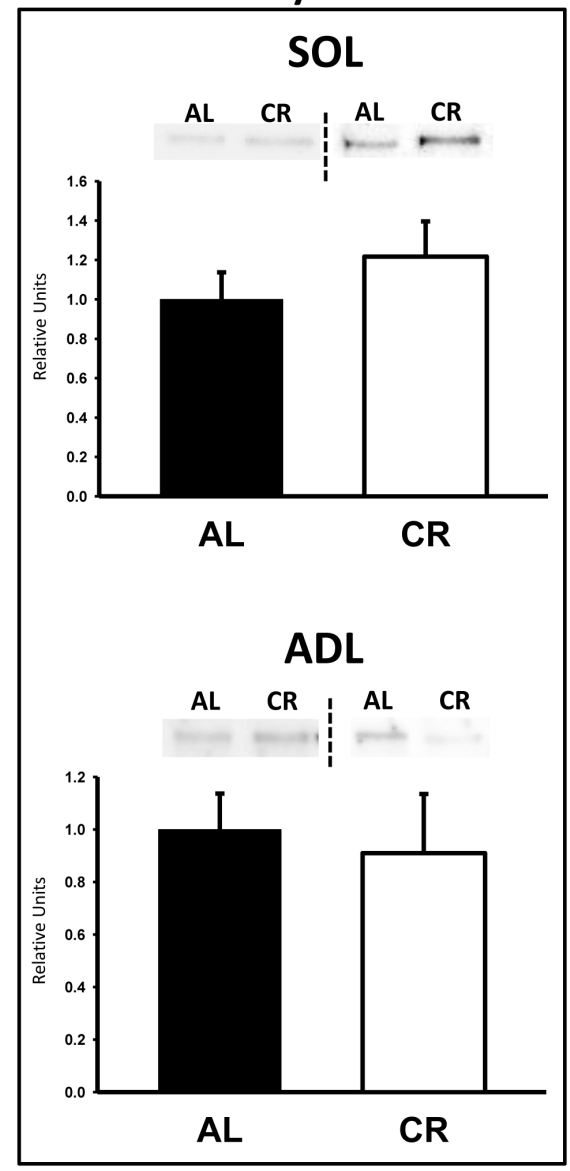

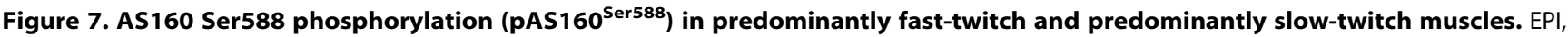
epitrochlearis; GN, gastrocnemius; TA, tibialis anterior; PLN, plantaris; SOL, soleus; ADL, adductor longus. Filled bars are the AL group and open bars are the CR group. Values are normalized to the average value of the $A L$ samples on each blot. ${ }^{*} P<0.05, C R$ versus $A L$. Data are means $\pm S E$. $n=6-$ 8 rats per treatment group.

doi:10.1371/journal.pone.0065118.g007

\section{Muscle Glucose-6-phosphate and Fructose-6-phosphate Concentrations}

There were no significant differences between AL and GR groups in either glucose-6-phosphate or fructose-6-phosphate concentrations in any of the muscles studied (Table 2).

\section{Discussion}

CR rats compared to AL rats had greater whole body insulin sensitivity that was, at least in part, attributable to CR effects on glucose uptake by multiple skeletal muscles, including the epitrochlearis, gastrocnemius, and tibialis anterior muscles. Because previous studies have established that improved in vivo insulin sensitivity is a hallmark of CR $[1,2,3,4,6,7]$, it was not unexpected that glucose uptake was greater in several insulinstimulated skeletal muscles of CR versus AL rats during the clamp. However, no CR effect on glucose uptake was found in several other muscles (plantaris, soleus and adductor longus). To gain insights into possible mechanisms for the heterogeneity of CR effects on in vivo muscle glucose uptake, we evaluated muscle fiber type, phosphorylation of several key insulin signaling proteins,
GLUT4 and hexokinase protein abundance, and concentrations of muscle metabolites.

Each of the muscles with greater glucose uptake in CR rats was a predominantly fast-twitch muscle, and neither of the predominantly slow-twitch muscles was characterized by a CR-induced increase in glucose uptake. Because insulin-stimulated glucose uptake is higher in muscles enriched with slow-twitch fibers $[38,39]$, a shift in fast-twitch muscle to a higher percentage of slowtwitch fibers would be predicted to favor greater glucose uptake. However, fiber type composition did not significantly differ between $\mathrm{AL}$ and $\mathrm{CR}$ rats for any of the six muscles that were studied, so the CR-induced muscle-specific increase in glucose uptake cannot be attributed to altered fiber type composition based on MHC profile. The current observation of increased whole body glucose disposal concomitant with no significant CR effect on soleus glucose uptake in vivo was consistent with the results of Escriva and colleagues [7]. They compared 8 month-old CR rats to age-matched AL rats during a euglycemic-hyperinsulinemic clamp and reported no significant diet effect on soleus glucose uptake along with a greater glucose infusion rate in the CR rats. They also found no significant diet effect for 8 mo-old rats on glucose uptake by either the diaphragm [7] which has a mixed 


\section{GLUT4 Abundance}
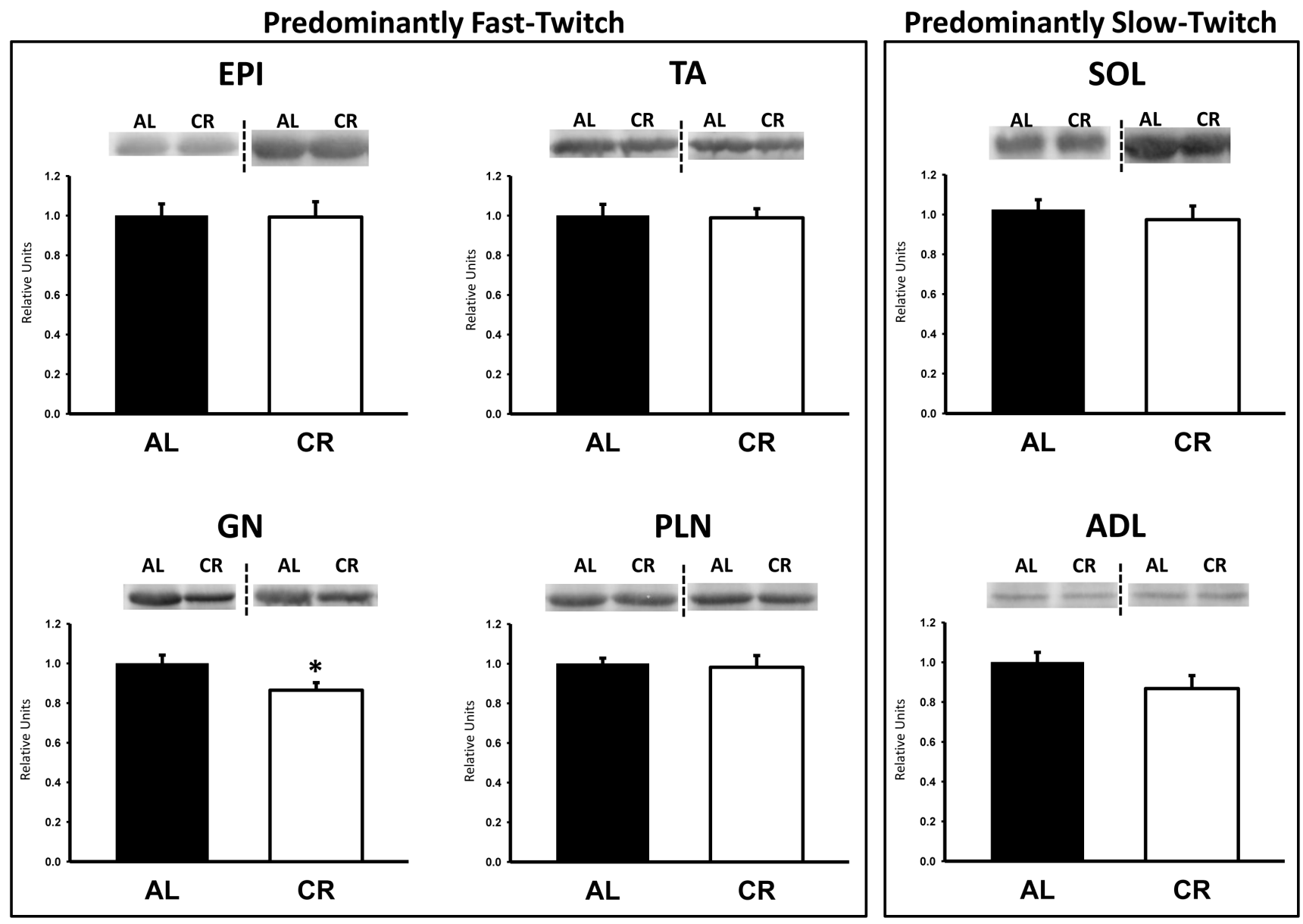

Figure 8. GLUT4 protein abundance in predominantly fast-twitch and predominantly slow-twitch muscles. EPI, epitrochlearis; GN, gastrocnemius; TA, tibialis anterior; PLN, plantaris; SOL, soleus; ADL, adductor longus. Filled bars are the AL group and open bars are the CR group. Values are normalized to the average value of the $A L$ samples on each blot. ${ }^{*} \mathrm{P}<0.05, \mathrm{CR}$ versus $\mathrm{AL}$. Data are means $\pm S E$. $\mathrm{n}=8-13$ rats per treatment group.

doi:10.1371/journal.pone.0065118.g008

fiber type composition (18\% type I, $24 \%$ type IIA, $36 \%$ type IIB, $22 \%$ type IIX) [40] or by the quadriceps which has a fiber type composition (5\% type I, $7 \%$ type IIA, $66 \%$ type IIB, $22 \%$ type IIX) [41] that is quite similar to our results for the epitrochlearis. In the current study, we observed no diet effect on glucose uptake by the plantaris which has a fiber type profile very similar to the gastrocnemius. Thus, although available data suggests that CR effects on insulin-stimulated glucose uptake in vivo may be more common in fast-twitch compared to slow-twitch muscles, the muscle heterogeneity for CR-effects cannot be predicted solely on the basis of muscle fiber type composition.

The capacity for insulin-stimulated glucose uptake of skeletal muscle correlates with the muscle's GLUT4 protein content [38], but GLUT4 abundance was not significantly increased by CR in any of the muscles studied. However, glucose uptake rate depends on translocation of GLUT4 to the cell surface of membranes. We previously reported that the cell surface GLUT4 levels of insulinstimulated epitrochlearis muscles ex vivo are greater for CR compared to AL rats [15]. In this context, one possibility is that the muscle-specific effects of CR on glucose uptake were attributable to muscle-specific effects on cell surface GLUT4 content. Accordingly, it would be valuable to determine the effect of GR on insulin-stimulated cell surface GLUT4 translocation in multiple skeletal muscles in vivo.

Many previous studies have documented CR-induced increases in insulin-stimulated glucose uptake by isolated skeletal muscles $[10,12,13,14,15,19,20,22,25,42,43]$. Especially relevant to the current research is our earlier study that evaluated ex vivo glucose uptake by epitrochlearis muscles [22] from male 9-mo old FBN rats that were either AL or undergoing the same CR protocol as in the current study. Under both in vivo and ex vivo conditions, the epitrochlearis from $\mathrm{CR}$ compared to AL rats had enhanced insulin-stimulated glucose uptake concomitant with greater phosphorylation of Akt (Thr308 and Ser473) and AS160 (Thr642 and Ser588). We have previously shown that IR, Akt and AS160 protein levels in the epitrochlearis (as well as other muscles) do not differ for AL compared to GR rats [22,33]. Using a highly selective Akt inhibitor to eliminate the CR-related increase in Akt phosphorylation, we were able to also eliminate the CR-induced increases in AS160 phosphorylation and glucose uptake by the isolated epitrochlearis [24]. These results provided compelling evidence that CR effects on Akt phosphorylation are essential for the GR effects on glucose uptake, at least under ex vivo conditions. The $\mathrm{CR}$ effects on insulin signaling in the 


\section{Hexokinase Abundance}

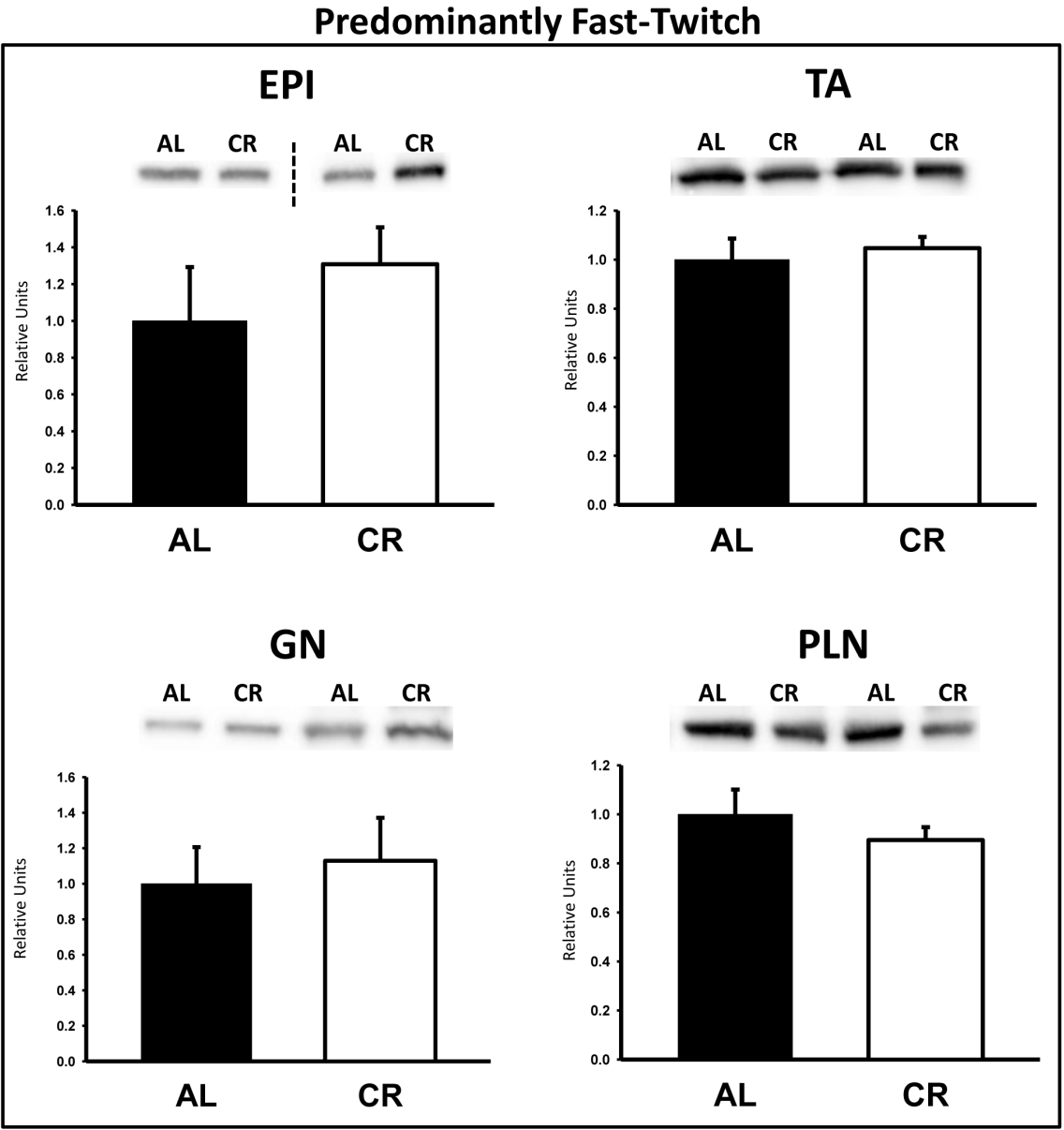

Predominantly Slow-Twitch

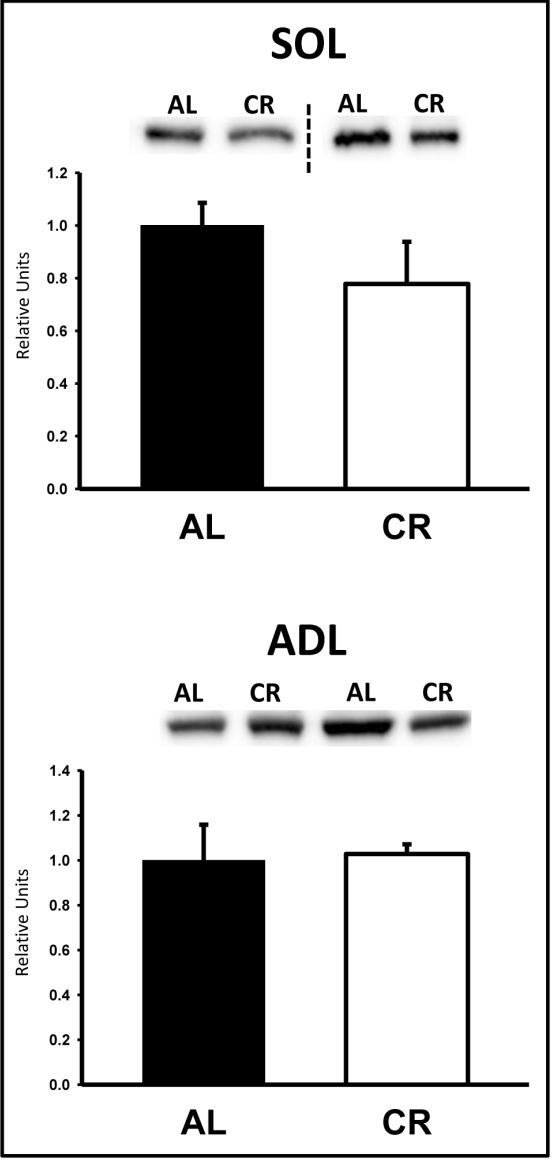

Figure 9. Hexokinase protein abundance in predominantly fast-twitch and predominantly slow-twitch muscles. $\mathrm{EPI}$, epitrochlearis; GN, gastrocnemius; TA, tibialis anterior; PLN, plantaris; SOL, soleus; ADL, adductor longus. Filled bars are the AL group and open bars are the CR group. Values are normalized to the average value of the AL samples on each blot. Data are means $\pm S E . n=7-8$ rats per treatment group. doi:10.1371/journal.pone.0065118.g009

epitrochlearis ex vivo correspond closely to the CR effects for insulin signaling in vivo. Therefore it seems reasonable to suspect that the greater in vivo glucose uptake by the epitrochlearis for GR versus AL rats may also rely on greater Akt activation.

Consistent with the results for the epitrochlearis, the other two muscles characterized by greater in vivo glucose uptake for GR rats (gastrocnemius and tibialis anterior) were also accompanied by increased phosphorylation of Akt and AS160 in CR versus AL animals. The CR-induced increases in Akt and AS160 phosphorylation for the gastrocnemius and tibialis anterior may also play a role in the CR-induced increase in insulin-stimulated glucose uptake in these muscles. In contrast, the absence of greater AS160

Table 2. Tissue concentrations of glucose-6-phosphate and fructose-6-phosphate in rat skeletal muscle.

\begin{tabular}{|c|c|c|c|c|}
\hline & \multicolumn{2}{|c|}{ Glucose-6-Phosphate $(\mu \mathrm{mol} / \mathrm{g})$} & \multicolumn{2}{|c|}{ Fructose-6-Phosphate $(\mu \mathrm{mol} / \mathrm{g})$} \\
\hline & AL & CR & AL & CR \\
\hline Epitrochlearis & $0.596 \pm 0.164$ & $0.759 \pm 0.219$ & $0.154 \pm 0.038$ & $0.155 \pm 0.049$ \\
\hline Gastrocnemius & $0.119 \pm 0.038$ & $0.163 \pm 0.038$ & $0.023 \pm 0.007$ & $0.037 \pm 0.008$ \\
\hline Tibialis Anterior & $0.366 \pm 0.045$ & $0.395 \pm 0.073$ & $0.070 \pm 0.010$ & $0.083 \pm 0.018$ \\
\hline Plantaris & $0.174 \pm 0.031$ & $0.268 \pm 0.050$ & $0.046 \pm 0.009$ & $0.070 \pm 0.009$ \\
\hline Soleus & $0.106 \pm 0.022$ & $0.127 \pm 0.029$ & $0.049 \pm 0.006$ & $0.054 \pm 0.004$ \\
\hline Adductor Longus & $0.283 \pm 0.035$ & $0.278 \pm 0.039$ & $0.065 \pm 0.012$ & $0.077 \pm 0.016$ \\
\hline
\end{tabular}

Values are means $\pm S E$. Ad libitum $(A L)$ and calorie restricted $(C R)$ treatment groups, $n=7-8$.

doi:10.1371/journal.pone.0065118.t002 
phosphorylation in the plantaris and adductor longus muscles of GR versus AL rats may be related to the lack of a CR effect on insulin-stimulated glucose uptake in either of these muscles.

The lack of a significant CR effect on in vivo glucose uptake by the soleus in the current study confirmed the observations of Escriva et al. [7]. We extended the earlier results by also demonstrating that in vivo Akt and AS160 phosphorylation of the soleus were greater for CR versus AL rats. Given the CRrelated increase in phosphorylation of Akt and AS160 that we found in the insulin-stimulated soleus, what might account for the lack of a concomitant CR-induced increase in insulin-stimulated glucose uptake in this muscle? A novel method that Wasserman and colleagues developed to identify the determinants of in vivo glucose uptake in rat skeletal muscle provides information that is relevant to answering this question [44,45]. Based on their analysis, they concluded that during a euglycemic-hyperinsulinemic clamp in ad libitum fed rats, glucose transport across the sarcolemma was not the major determinant for glucose uptake by the insulin-stimulated soleus. Instead, they proposed that glucose delivery and/or glucose phosphorylation by hexokinase were the crucial determinants for insulin-stimulated glucose uptake by the soleus in vivo. With regard to these regulatory steps, we did not find CR-induced changes in either hexokinase abundance or G6P concentration, and we are unaware of any information on the possibility that CR alters blood flow to the soleus. Regardless, if in vivo glucose uptake by the soleus of AL rats was not limited by glucose transport, then the CR-induced elevation of Akt and AS160 phosphorylation would not be expected to result in a higher rate of in vivo glucose uptake by the soleus (because these signaling proteins are known to be important for glucose transport, but not for regulating either glucose delivery or glucose phosphorylation). Notably, Wasserman's group also studied the gastrocnemius and vastus lateralis and reported that, in contrast to the type I soleus, glucose transport was a limiting factor for in vivo glucose uptake by these muscles. Their results in these predominantly type II muscles may be relevant for our observation of substantial CR-induced increases in insulin-stimulated glucose uptake by the gastrocnemius, epitrochlearis and tibialis anterior.

In an earlier study, we found that CR resulted in greater insulinstimulated glucose uptake in isolated soleus muscles in 9 mo-old FBN rats subjected to the same CR protocol as in the current study [22]. What might account for the differing results for GR effects on glucose uptake by insulin-stimulated soleus ex vivo [22] versus in vivo? The divergent outcomes may be explained by a difference in ex vivo versus in vivo conditions, including: 1) the influence of blood flow (a key determinant of glucose delivery), 2) presence of circulating hormones and cytokines (e.g., adiponectin, resistin, leptin, cortiscosterone, etc.), 3) circulating fuels, 4) neuroregulation, and 5) contractile activity of skeletal muscles. Glucose was absent from the ex vivo incubation media (only 2DG

\section{References}

1. Arciero PJ, Vukovich MD, Holloszy JO, Racette SB, Kohrt WM (1999) Comparison of short-term diet and exercise on insulin action in individuals with abnormal glucose tolerance. J Appl Physiol 86: 1930-1935.

2. Wing RR, Blair EH, Bononi P, Marcus MD, Watanabe R, et al. (1994) Caloric restriction per se is a significant factor in improvements in glycemic control and insulin sensitivity during weight loss in obese NIDDM patients. Diabetes Care 17: $30-36$.

3. Petersen KF, Dufour S, Morino K, Yoo PS, Cline GW, et al. (2012) Reversal of muscle insulin resistance by weight reduction in young, lean, insulin-resistant offspring of parents with type 2 diabetes. Proc Natl Acad Sci U S A.

4. Kemnitz JW, Roecker EB, Weindruch R, Elson DF, Baum ST, et al. (1994) Dietary restriction increases insulin sensitivity and lowers blood glucose in rhesus monkeys. Am J Physiol 266: E540-547. was included), whereas glucose was, of course, present in vivo. The concentration of insulin in vivo $(\sim 140 \mu \mathrm{U} / \mathrm{ml})$ was $\sim 30 \%$ lower than during the ex vivo condition $(200 \mu \mathrm{U} / \mathrm{ml})$, and the duration of insulin stimulation was almost 3 -fold longer during the in vivo clamp (145 minutes) compared to ex vivo incubations (50 minutes). It is possible that a longer exposure to insulin may attenuate the effect of CR on glucose uptake in vivo, although it should be noted that Akt phosphorylation was greater in the soleus of CR versus $\mathrm{AL}$ rats at the end of the clamp. To reconcile the results obtained using the different models, it would be valuable to assess in vivo glucose uptake with only 50 minutes of elevated insulin. It would also be useful to perform an experiment in which soleus muscles from AL and CR rats were studied ex vivo with the glucose and insulin concentrations and duration of elevated insulin matched to the values for the clamp procedure.

In conclusion, the current data revealed that CR leads to greater whole body glucose disposal during a euglycemichyperinsulinemic clamp that is in part attributable to substantially elevated in vivo glucose uptake by multiple predominantly fasttwitch skeletal muscles. The results also clearly demonstrated that CR does not uniformly enhance either insulin signaling or glucose uptake in all skeletal muscles under these in vivo conditions. The observations in this study provide novel support for the idea that CR effects on in vivo glucose uptake may be, at least in some predominantly fast-twitch muscles, related to enhancing Akt and AS160 phosphorylation. However, the results for the soleus revealed that greater Akt and AS160 phosphorylation are not sufficient for enhanced in vivo glucose uptake by all muscles. It would be valuable to determine the influence of CR on GLUT4 translocation of multiple skeletal muscles when stimulated by insulin in vivo. It would also be useful to perform experiments that identify the underlying causes that account for CR's different effects on glucose uptake by the soleus under ex vivo versus in vivo conditions. Understanding CR effects under in vivo conditions is our ultimate goal, but the thoughtful use of multiple approaches offers the best opportunity to elucidate the complex biological consequences of CR.

\section{Acknowledgments}

The authors thank the staff of the University of Michigan Metabolomics Core for their technical assistance. NS and DAS contributed equally to this manuscript.

\section{Author Contributions}

Conceived and designed the experiments: NS DAS GDC. Performed the experiments: NS DAS CMC EBA NRO. Analyzed the data: NS DAS GDC. Contributed reagents/materials/analysis tools: NRQ. Wrote the paper: NS DAS GDG.
5. Lawler DF, Larson BT, Ballam JM, Smith GK, Biery DN, et al. (2008) Diet restriction and ageing in the dog: major observations over two decades. $\mathrm{Br} \mathrm{J}$ Nutr 99: 793-805.

6. Gupta G, She L, Ma XH, Yang XM, Hu M, et al. (2000) Aging does not contribute to the decline in insulin action on storage of muscle glycogen in rats. Am J Physiol Regul Integr Comp Physiol 278: R111-117.

7. Escriva F, Gavete ML, Fermin Y, Perez C, Gallardo N, et al. (2007) Effect of age and moderate food restriction on insulin sensitivity in Wistar rats: role of adiposity. J Endocrinol 194: 131-141.

8. Schenk S, McCurdy CE, Philp A, Chen MZ, Holliday MJ, et al. (2011) Sirt1 enhances skeletal muscle insulin sensitivity in mice during caloric restriction. J Clin Invest 121: 4281-4288.

9. DeFronzo RA, Jacot E, Jequier E, Maeder E, Wahren J, et al. (1981) The effect of insulin on the disposal of intravenous glucose. Results from indirect 
calorimetry and hepatic and femoral venous catheterization. Diabetes 30: 10001007.

10. McCurdy CE, Cartee GD (2005) Akt2 is essential for the full effect of calorie restriction on insulin-stimulated glucose uptake in skeletal muscle. Diabetes 54: 1349-1356.

11. Gazdag AC, Dumke CL, Kahn CR, Cartee GD (1999) Calorie restriction increases insulin-stimulated glucose transport in skeletal muscle from IRS-1 knockout mice. Diabetes 48: 1930-1936.

12. McCurdy GE, Davidson RT, Cartee GD (2003) Brief calorie restriction increases Akt2 phosphorylation in insulin-stimulated rat skeletal muscle. Am J Physiol Endocrinol Metab 285: E693-700.

13. McCurdy CE, Davidson RT, Cartee GD (2005) Calorie restriction increases the ratio of phosphatidylinositol 3-kinase catalytic to regulatory subunits in rat skeletal muscle. Am J Physiol Endocrinol Metab 288: E996-E1001.

14. Dean DJ, Cartee GD (1996) Brief dietary restriction increases skeletal muscle glucose transport in old Fischer 344 rats. J Gerontol A Biol Sci Med Sci 51: B208-213.

15. Dean DJ, Brozinick JT Jr, Cushman SW, Cartee GD (1998) Calorie restriction increases cell surface GLUT-4 in insulin-stimulated skeletal muscle. Am J Physiol 275: E957-964.

16. Dean DJ, Gazdag AC, Wetter TJ, Cartee GD (1998) Comparison of the effects of 20 days and 15 months of calorie restriction on male Fischer 344 rats. Aging (Milano) 10: 303-307.

17. Dean DJ, Cartee GD (2000) Calorie restriction increases insulin-stimulated tyrosine phosphorylation of insulin receptor and insulin receptor substrate-1 in rat skeletal muscle. Acta Physiol Scand 169: 133-139.

18. Gazdag AC, Sullivan S, Kemnitz JW, Cartee GD (2000) Effect of long-term caloric restriction on GLUT4, phosphatidylinositol-3 kinase p85 subunit, and insulin receptor substrate-1 protein levels in rhesus monkey skeletal muscle. J Gerontol A Biol Sci Med Sci 55: B44-46; discussion B47-48.

19. Gazdag AC, Wetter TJ, Davidson RT, Robinson KA, Buse MG, et al. (2000) Lower calorie intake enhances muscle insulin action and reduces hexosamine levels. Am J Physiol Regul Integr Comp Physiol 278: R504-512.

20. Cartee GD, Dean DJ (1994) Glucose transport with brief dietary restriction: heterogenous responses in muscles. Am J Physiol 266: E946-952.

21. Cartee GD, Kietzke EW, Briggs-Tung C (1994) Adaptation of muscle glucose transport with caloric restriction in adult, middle-aged, and old rats. Am J Physiol 266: R1443-1447.

22. Sharma N, Arias EB, Bhat AD, Sequea DA, Ho S, et al. (2011) Mechanisms for increased insulin-stimulated Akt phosphorylation and glucose uptake in fast- and slow-twitch skeletal muscles of calorie-restricted rats. Am J Physiol Endocrinol Metab 300: E966-978.

23. Ivy JL, Young JC, Craig BW, Kohrt WM, Holloszy JO (1991) Ageing, exercise and food restriction: effects on skeletal muscle glucose uptake. Mech Ageing Dev 61: 123-133.

24. Sharma N, Arias EB, Sequea DA, Cartee GD (2012) Preventing the calorie restriction-induced increase in insulin-stimulated Akt2 phosphorylation eliminates calorie restriction's effect on glucose uptake in skeletal muscle. Biochim Biophys Acta 1822: 1735-1740.

25. Sequea DA, Sharma N, Arias EB, Cartee GD (2012) Calorie Restriction Enhances Insulin-Stimulated Glucose Uptake and Akt Phosphorylation in Both Fast-Twitch and Slow-Twitch Skeletal Muscle of 24-Month-Old Rats. J Gerontol A Biol Sci Med Sci.

26. Sharma N, Sequea DA, Arias EB, Cartee GD (2012) Greater insulin-mediated Akt phosphorylation concomitant with heterogeneous effects on phosphorylation of Akt substrates in soleus of calorie restricted rats. Am J Physiol Regul Integr Comp Physiol.
27. Kane S, Sano H, Liu SC, Asara JM, Lane WS, et al. (2002) A method to identify serine kinase substrates. Akt phosphorylates a novel adipocyte protein with a Rab GTPase-activating protein (GAP) domain. J Biol Chem 277: 22115-22118.

28. Sano H, Kane S, Sano E, Miinea CP, Asara JM, et al. (2003) Insulin-stimulated phosphorylation of a Rab GTPase-activating protein regulates GLUT4 translocation. J Biol Chem 278: 14599-14602.

29. Cartee GD, Wojtaszewski JF (2007) Role of Akt substrate of $160 \mathrm{kDa}$ in insulinstimulated and contraction-stimulated glucose transport. Appl Physiol Nutr Metab 32: 557-566.

30. Cartee GD, Funai K (2009) Exercise and insulin: Convergence or divergence at AS160 and TBC1D1? Exerc Sport Sci Rev 37: 188-195.

31. Kramer HF, Witczak CA, Taylor EB, Fujii N, Hirshman MF, et al. (2006) AS160 regulates insulin- and contraction-stimulated glucose uptake in mouse skeletal muscle. J Biol Chem 281: 31478-31485.

32. Sakamoto K, Holman GD (2008) Emerging role for AS160/TBC1D4 and TBC1D1 in the regulation of GLUT4 traffic. Am J Physiol Endocrinol Metab 295: E29-37.

33. Sharma N, Castorena CM, Cartee GD (2012) Tissue-specific responses of IGF1/insulin and mTOR signaling in calorie restricted rats. PLoS One 7: e38835.

34. Feuers RJ, Duffy PH, Chen F, Desai V, Oriaku E, et al. (1995) Intermediary metabolism and antoxidant systems. In: Hart RW, editor. Dietary Restriction: Implications for the Design and Interpretation of Toxicity and Carcinogenecity Studies. Washington, D.C.: Int Life Sci Inst. 181-195.

35. Halseth AE, Bracy DP, Wasserman DH (1999) Overexpression of hexokinase II increases insulinand exercise-stimulated muscle glucose uptake in vivo. Am J Physiol 276: E70-77.

36. Talmadge RJ, Roy RR (1993) Electrophoretic separation of rat skeletal muscle myosin heavy-chain isoforms. J Appl Physiol 75: 2337-2340.

37. Lang G, Michal G (1974) D-Glucose-6-phosphate and D-fructose 6-phosphate. In: Bergmeyer H-U, editor. Methods of Enzymatic Analysis (2nd ed). New York: Academic Press. 1238-1242.

38. Henriksen EJ, Bourey RE, Rodnick KJ, Koranyi L, Permutt MA, et al. (1990) Glucose transporter protein content and glucose transport capacity in rat skeletal muscles. Am J Physiol 259: E593-598.

39. James DE, Jenkins AB, Kraegen EW (1985) Heterogeneity of insulin action in individual muscles in vivo: euglycemic clamp studies in rats. Am J Physiol 248: E567-574.

40. Geiger PC, Bailey JP, Zhan WZ, Mantilla CB, Sieck GC (2003) Denervationinduced changes in myosin heavy chain expression in the rat diaphragm muscle. J Appl Physiol 95: 611-619.

41. Tonge DP, Jones SW, Parr T, Bardsley R, Doherty M, et al. (2010) Beta2adrenergic agonist-induced hypertrophy of the quadriceps skeletal muscle does not modulate disease severity in the rodent meniscectomy model of osteoarthritis. Osteoarthritis Cartilage 18: 555-562.

42. Davidson RT, Arias EB, Cartee GD (2002) Calorie restriction increases muscle insulin action but not IRS-1-, IRS-2-, or phosphotyrosine-PI 3-kinase. Am J Physiol Endocrinol Metab 282: E270-276.

43. Gazdag AC, Tucker MZ, Turcotte LP, Dean DJ, Cartee GD (1998) Effect of extracellular palmitate on 2-deoxy-d-glucose uptake in muscle from Ad libitum fed and calorie restricted rats. Biochem Biophys Res Commun 252: 733-737.

44. Halseth AE, Bracy DP, Wasserman DH (2001) Functional limitations to glucose uptake in muscles comprised of different fiber types. Am J Physiol Endocrinol Metab 280: E994-999.

45. Petersen HA, Fueger PT, Bracy DP, Wasserman DH, Halseth AE (2003) Fiber type-specific determinants of Vmax for insulin-stimulated muscle glucose uptake in vivo. Am J Physiol Endocrinol Metab 284: E541-548. 